Revista Brasileira de Farmacognosia Brazilian Journal of Pharmacognosy 21(6): 1000-1005, Nov./Dec. 2011

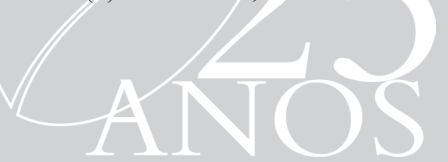

Article

Received 18 Oct 2010

Accepted 12 Jan 2011

Available online 23 Sep 2011

Keywords:

antioxidant

apoptosis

cytotoxicity

DNA ladder

micronucleus

ISSN 0102-695X

http://dx.doi.org/10.1590/S0102-

$695 \mathrm{X} 2011005000176$

\section{Protective action against chemical-induced genotoxicity and free radical scavenging activities of Stryphnodendron adstringens ("barbatimão") leaf extracts}

\author{
Plínio R. dos Santos Filho, ${ }^{1}$ Lidiane A. Ferreira, ${ }^{2}$ Cibele M. C. \\ Paiva Gouvêa ${ }^{*}$
}

${ }^{1}$ Departamento de Biologia Vegetal, Laboratório de Bioquímica de Plantas, Instituto de Biologia, Universidade Estadual de Campinas, Brazil,

${ }^{2}$ Instituto de Ciencias da Natureza, Universidade Federal de Alfenas, Brazil.

\begin{abstract}
The present study describes for the first time the antigenotoxic and antioxidant properties of Stryphnodendron adstringens (Mart.) Coville, Fabaceae ("barbatimão") leaves. The aqueous (AEB), water fraction (WFB) and ethanolic (EEB) extracts of leaves were obtained and they presented high content of phenolic compounds, flavonoids and proanthocyanidins. WFB and EEB inhibited the genotoxicity induced by cyclophosphamide. WFB inhibited the DNA lesion formation and both WFB and EEB decreased significantly $(p<0.05)$ micronucleus formation. All extracts also showed high DPPH radical scavenging activity and reducing power. In conclusion all extracts presented antioxidant activity and WFB and EEB protected cells from genotoxicity induced by cyclophosphamide in rat bone marrow cells. Thus, our results support the beneficial effects of the barbatimão extracts as an anticarcinogenic agent.
\end{abstract}

\section{Introduction}

The use of herbal medicine (leaves, flowers, roots, stems and berries) is a traditional form of healthcare (Diwanay et al., 2004). In this context, an important focus of the search is to understand the true efficacy of plant materials and determine its mechanism of action in different experimental models (RomeroJiménez et al., 2005). Although human body is equipped with self defense mechanisms such as detoxification process through various enzymes, serious exposure to dangerous chemicals can cause changes in the genetic material (mutations) leading to carcinogenic events (Edenharder et al., 1998; Belitsky \& Yakubovskaya, 2008). Cyclophosphamide (CP), an antineoplastic agent, and its metabolites can bind DNA, causing damage that may result in chromosome breaks, micronucleus formation and cell death (Murata et al., 2004). Beyond that, $\mathrm{CP}$ alters the redox balance of tissues suggesting that physiological and biochemical disturbances may result from oxidative stress (Sugumar et al., 2007).

Oxidative stress is an important factor in the genesis of several pathologies, from cancer to cardiovascular and degenerative diseases. Human cells are constantly exposed to reactive oxygen species (ROS) generated by a number of biotic and abiotic factors that can harm the cells. Antioxidants provide protection to living organisms from damage caused by uncontrolled production of ROS and the concomitant oxidation of nucleic acids, proteins, lipids and carbohydrates, which may subsequently determine mutagenesis and diseases related to DNA damage (Halliwell, 2007a; 2007b). Anticarcinogens/anti-mutagens, often used in traditional medicine, can prevent or revert some of the effects produced by carcinogens. However, knowledge about the mechanism of action of many anti-carcinogens, e.g., phytochemicals, is still poor (Paolini \& Nestle, 2003).

Because of their wide spectrum of activities, constituents such as phenolic compounds and flavonoids have been the subject of many investigations. An important but often neglected group of polyphenolic compounds is that of the tannins, which are widely distributed in higher plants and they have proven to possess health benefits (Okuda, 2005).

Stryphnodendron adstringens (Mart.) Coville, Fabaceae, known as 'barbatimão', occurs in the central savannah region of Brazil and is a rich source of tannins (Santos et al., 2002) and proanthocyanidins (Mello et al., 1996a; 1996b; 1999; Ishida et al., 2006; Lopes et al., 2008). Stem bark is the main part of the plant used popularly as an anti-inflammatory, astringent, in the treatment of wounds and vaginal infections (Panizza et 
al., 1988; Lopes et al., 2005). Several reports have proven the anti-ulcerogenic, anti-inflammatory, antinociceptive and antimicrobial (Lima et al., 1998; Audi et al., 1999; Ishida et al., 2006; Ishida et al., 2009; Melo et al., 2007) activities of bark extract of $S$. adstringens. However there are few reports on the toxicity of barbatimão leaf extracts (Almeida et al., 2010). Thus, the aim of the present study was to determine the antigenotoxic activity of $S$. adstringens leaf extracts on genotoxicity induced by $\mathrm{CP}$ in rat bone marrow cells and the in vitro antioxidant potential of the extracts.

\section{Materials and Methods}

\section{Plant material}

Leaves of Stryphnodendron adstringens (Mart.) Coville, Fabaceae, were collected in Alfenas (Minas Gerais, Brazil) in Julho/2007 and deposited at the Herbarium of the Universidade Federal de Alfenas, Brazil (voucher specimen N. 196).

\section{Preparation of leaf extract}

The leaves were dried at $30{ }^{\circ} \mathrm{C}$ and then pulverized. The aqueous extract (AEB) was obtained by decoction of $10 \mathrm{~g}$ of leaves in $100 \mathrm{~mL}$ of deionized water, at $90{ }^{\circ} \mathrm{C}$, for $10 \mathrm{~min}$ and filtered. The water fraction (WFB) remained after powder leaf extraction (100 g) with $70 \%(\mathrm{v} / \mathrm{v})$ acetone aqueous solution $(1 \mathrm{~L})$ and partitioning with ethyl acetate. The ethanol extract (EEB) was obtained by maceration of $100 \mathrm{~g}$ of powder in $1 \mathrm{~L}$ of $70 \%(\mathrm{v} / \mathrm{v})$ ethanol aqueous solution and the solvent was evaporated in a rotavapor under reduced pressure. All extracts were lyophilized and stored at $-20{ }^{\circ} \mathrm{C}$, until use. For use the extracts were dissolved in deionized water.

\section{Determination of phenolic, flavonoid and proanthocyanidins content}

The total phenolic compounds were determined using Folin-Ciocalteau's method (Rai et al., 2006), total flavonoids using aluminum chelating method (Ebrahimzadeh et al., 2008) and proanthocyanidins content was obtained after acid depolymerization to the corresponding anthocyanidins (Rösch et al., 2003).

\section{Animals and treatment}

Male Wistar rats (120 $20 \mathrm{~g})$ were housed with access to food and water ad libitum and light-dark cycles of $12 \mathrm{~h}$ were used. The animals were divided into eight groups (each group consisted of six rats). Control group received water; $\mathrm{CP}$ group received cyclophosphamide (40 mg/kg, per gavage), $24 \mathrm{~h}$ before euthanasia; extract groups received $500 \mathrm{mg} / \mathrm{kg}$ body wt, per gavage, for 7 days and extract $+\mathrm{CP}$ groups received the extract for 7 days and CP $24 \mathrm{~h}$ before euthanasia. After euthanasia, with overdose of anesthesia, the femur was quickly removed and the bone marrow cells collected.

\section{DNA isolation and electrophoresis}

The DNA of the bone marrow cells from the left femur was isolated using the SDS/Proteinase K/RNase A extraction method (DeSierve et al., 2002). Samples were electrophoresed in $0.8 \%(\mathrm{w} / \mathrm{v})$ agarose gel and DNA was visualized by ethidium bromide staining. The presence of apoptosis was indicated by the appearance of a ladder of oligonucleosomal DNA fragments that are approximately 180-200 bp multiples and the necrosis by the appearance of a smear on the agarose gel.

\section{Micronucleus assay}

This assay was performed according to Nakagawa et al. (2008), with modifications. Bone marrow cells of the right femur of each animal was flushed out as a fine suspension with $2.5 \mathrm{~mL}$ fetal bovine serum (FBS) and centrifuged at $1,000 \times \mathrm{g}$ for $5 \mathrm{~min}$. The pellet was resuspended in $0.5 \mathrm{~mL}$ saline. The suspension was smeared onto the precleaned air-dried slides following fixing in $100 \%$ methanol for $5 \mathrm{~min}$ and stained with Giemsa. One thousand total erythrocytes (polychromatic and normochromatic) were scored per animal. The frequency of micronucleated polychromatic erythrocytes (MNPCE) and the total PCE and NCE were determined.

\section{Antioxidant assays}

\section{Total antioxidant capacity}

The total antioxidant capacity was determined (Prieto et al., 1999), and the results were expressed as equivalents of ascorbic acid.

\section{DPPH assay}

The hydrogen atoms or electron donation ability of the extracts was measured from the bleaching of purple colored methanol solution of DPPH according to Yen \& $\mathrm{Wu}$ (1999). L-ascorbic acid and BHT were used as the reference standards.

\section{Reducing power}

The reducing power of the extracts was determined according to the method of Oyaizu (1986), using L-ascorbic acid and BHT as the reference standards. 


\section{Statistical analysis}

Data were analyzed using ANOVA with post hoc analysis by Tukey test, when $p<0.05$. Results are expressed as mean \pm standard error of the mean (SE).

\section{Results and Discussion}

In our study, the chemopreventive and antioxidant properties of barbatimão leaf extracts were evaluated. We used cyclophosphamide (CP), a genotoxic agent widely used both, in clinical treatment and experimentally (Murata et al., 2004; Nagar, 2010). $\mathrm{CP}$ belongs to the group of $\mathrm{N}$-lost compounds. It requires CYP450-dependent activation, yielding the active compound 4-hydroxy-cyclophosphamide. This molecule undergoes spontaneous decomposition to the biologically active alkylating species acrolein and phosphoramide mustard, which preferentially alkylates the N7 position of guanine. Since CP is a bifunctional compound, DNA alkylation gives rise to interstrand cross-links that are thought to be responsible for the induction of cell death (Murata et al., 2004). From the DNA fragmentation analysis, it can be seen that CP induced apoptosis, confirmed by the DNA ladder pattern (Figure 1). The AEB and WFB were not genotoxic, as they did not induce DNA lesion. The WFB was antigenotoxic, as it protected cells from the apoptotic effect of $\mathrm{CP}$ and it could be postulated that proanthocyanidins contributed to its activity, once, amongst the studied extracts, WFB presented the highest content of these compounds.

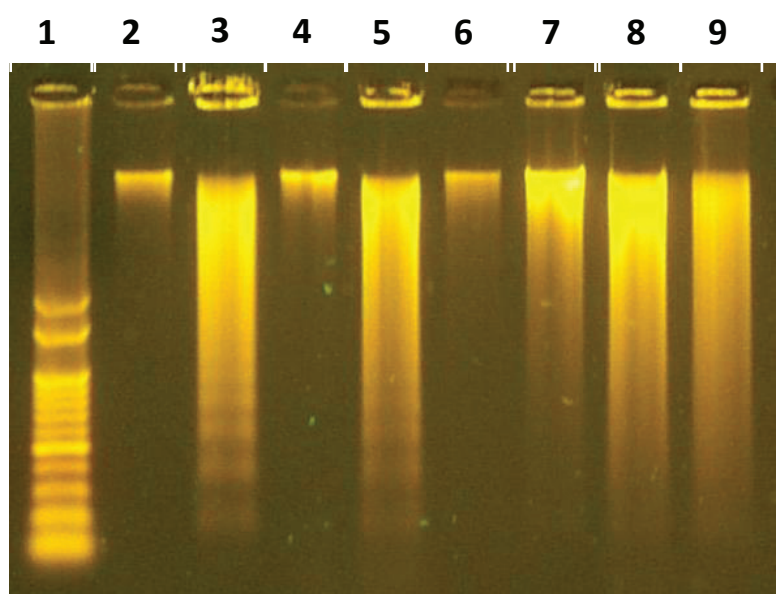

Figure 1. Agarose gel electrophoresis of bone marrow cells genomic DNA of control and treated rats. 1, 123 bp ladder marker; 2, Control; 3, Cyclophosphamide (CP); 4, Aqueous extract (AEB); 5, AEB plus CP; 6, Water fraction (WFB); 7, WFB plus CP; 8, ethanolic extract (EEB); 9, EEB plus CP. DNA ladder formation indicates apoptosis as seem in lanes 3 and 5 and DNA smear as seen in lanes 8 and 9 indicates necrosis. The results are representative of five independent experiments.
The quantitative assessment of micronucleus containing cells serves as a good indicator for the induction of structural and numerical chromosomal aberrations. Breakage of chromatids or chromosomes can result in micronuclei formation if an acentric fragment is produced; therefore assays detecting either chromosomal aberration or micronuclei are acceptable for detecting clastogenicity (Natarajan, 2002) and the micronucleus test is recommended by the Brazilian Health Surveillance Agency for phytotherapic preclinical toxicity studies (Anvisa, 2004). The results of micronucleus assay are shown in Table 1. The data of this test corroborates the findings of the DNA fragmentation test. A significant $(p<0.05)$ increase in the percentage of micronuclei was observed after treatment with CP as compared to the control and treated groups. Administration of $\mathrm{CP}$ in combination with extracts showed significant decrease $(p<0.001)$ in the percentage of micronuclei as compared to $\mathrm{CP}$ treated rats. In the groups treated with extracts the PCE/NCE ratio increased, indicating, possibly, a cell proliferation stimulation activity of the extracts. These results further confirm that the extracts were antigenotoxic. Our results are in agreement with Costa et al. (2010) who observed no genotoxic effect of the proanthocyanidin polymerrich fraction of stem bark of $S$. adstringens. This work reported no significant differences in the frequency of MNPCE induced by the fraction treatment when compared to the negative control. The fraction was also antimutagenic and this activity could be attributed to the tannin content and to its antioxidant activity, due to its ability to form complexes with other macromolecules. In the present work we observed an antigenotoxic activity of all extracts and that all of them exhibited antioxidant activity.

Table 1. Frequencies of micronucleated polychromatic erythrocytes (MNPCE), polychromatic erythrocytes (PCE) and normochromatic erythrocytes (NCE) in mouse bone marrow cells of control and treated groups.

\begin{tabular}{lcccc}
\hline \multicolumn{1}{c}{ Groups } & PCE & NCE & PCE/NCE & $\begin{array}{c}\text { MNPCE/ } \\
1000 \text { cells }\end{array}$ \\
\hline Control & $380.50 \pm 20.78^{\mathrm{a}}$ & $611.50 \pm 19,62^{\mathrm{a}}$ & $0.63 \pm 0.05^{\mathrm{a}}$ & $4.33 \pm 0.80^{\mathrm{a}}$ \\
CP & $240.16 \pm 26.91^{\mathrm{b}}$ & $697.33 \pm 31,42^{\mathrm{a}}$ & $0.35 \pm 0.06^{\mathrm{b}}$ & $31.83 \pm 6.00^{\mathrm{b}}$ \\
WFB & $664.00 \pm 44.32^{\mathrm{c}}$ & $323.16 \pm 42,53^{\mathrm{b}}$ & $2.23 \pm 0.29^{\mathrm{c}}$ & $9.16 \pm 2.02^{\mathrm{a}}$ \\
WFB $+\mathrm{CP}$ & $620.16 \pm 55.01^{\mathrm{c}}$ & $360.83 \pm 53,26^{\mathrm{b}}$ & $2.60 \pm 0.12^{\mathrm{c}}$ & $12.33 \pm 3.38^{\mathrm{a}}$ \\
EEB & $779.33 \pm 18.46^{\mathrm{c}}$ & $203.66 \pm 16.96^{\mathrm{b}}$ & $4.02 \pm 0.48^{\mathrm{d}}$ & $7.16 \pm 1.77^{\mathrm{a}}$ \\
EEB+CP & $635.50 \pm 65.49^{\mathrm{c}}$ & $341.50 \pm 61.25^{\mathrm{b}}$ & $2.51 \pm 0.82^{\mathrm{c}}$ & $12.16 \pm 2.08^{\mathrm{a}}$ \\
AEB & $803.00 \pm 43.54^{\mathrm{c}}$ & $191.83 \pm 43,67^{\mathrm{b}}$ & $5.19 \pm 0.93^{\mathrm{d}}$ & $2.16 \pm 0.54^{\mathrm{a}}$ \\
AEB $+C P$ & $738.50 \pm 12.34^{\mathrm{c}}$ & $254.66 \pm 11.87^{\mathrm{b}}$ & $2.96 \pm 0.22^{\mathrm{c}}$ & $4.00 \pm 0.85^{\mathrm{a}}$ \\
\hline AEB, $\mathrm{Cq}$ & & &
\end{tabular}

AEB, aqueous extract; WFB, water fraction and EEB, ethanolic extract of barbatimão leaves; $\mathrm{CP}$, cyclophosphamide. $\mathrm{N}=6$. A total of 6,000 cells were counted per group (1,000 cells per animal). The results are mean \pm SE. Different letters in the same column indicate significant difference $(p<0.05)$ by the Tukey test. 
The determination of main components of the extracts (Table 2) showed that EEB presented the higher phenolics and flavonoids content while the WFB presented the higher proanthocyanidins content. Phenolic compounds are regarded to be the most important antioxidative constituent of plants; hence correlations between the concentrations of plant phenolics and the total antioxidant capacities have been well reported (Gulcin et al., 2002; Oktay et al., 2003). The content of phenolic compounds in the extracts was higher than that reported to other previously examined sources of antioxidants (Hu et al., 2000; Mathew \& Abraham, 2004; Basile et al., 2005). It is important to point out that the WFB presented the highest amount of proanthocyanidins and it was expected since we used a recommend solvent system to better extract this class of compound (Foo \& Porter, 1980). We further confirm the proanthocyanidin content of the WFB by heating it with $5 \% \mathrm{HCl}$ in tertbutanol which yielded cyanidin as the principal pigment.

Table 2. Barbatimão leaf extracts total phenolic compounds, flavonoids and proanthocyanidins content.

\begin{tabular}{cccc}
\hline Extracts & \multicolumn{2}{c}{ Content } \\
\hline & Phenolics (\%) & Flavonoids (\%) & Proanthocyanidins $(\mu \mathrm{M})$ \\
\hline AEB & $32,00 \pm 2,05^{\mathrm{a}}$ & $5,02 \pm 0,29^{\mathrm{ab}}$ & $23.32 \pm 1.75^{\mathrm{a}}$ \\
WFB & $23,93 \pm 1,29^{\mathrm{b}}$ & $3,63 \pm 0,22^{\mathrm{a}}$ & $35.40 \pm 2.10^{\mathrm{b}}$ \\
EEB & $34,94 \pm 2,95^{\mathrm{a}}$ & $6,44 \pm 0,19^{\mathrm{b}}$ & $24.75 \pm 1.28^{\mathrm{a}}$
\end{tabular}

AEB, aqueous extract; WFB, water fraction and EEB, ethanolic extract of barbatimão leaves. The results are mean $\pm \mathrm{SE}$ of three independent experiments $(\mathrm{N}=5)$. Different letters in the same column indicate significant difference $(p<0.05)$ by the Tukey test.

It was observed that the amount of flavonoids in the analyzed barbatimão leaf extracts showed a high correlation with the total amount of phenolics and antioxidant activity. Extracts with high content of phenols and flavonoids are known to exhibit high antioxidant activity (Boudet, 2007).

All of the extracts tested presented antioxidant activity, and it could be attributed to the extract constituents. The total antioxidant capacity of the extracts was: $147.85 \pm 12.68,124.36 \pm 7.18$ and $148.64 \pm 8.41 \mathrm{mg}$ ascorbic acid/g extract, for AEB, WFB and EEB respectively. The extracts also showed strong DPPH scavenging activity (Figure 2A). The free radical DPPH scavenging activity of the extracts was concentration-dependent and the maximum activity was achieved with $62.00 \pm 0.91 \mu \mathrm{g} /$ $\mathrm{mL}$. The extracts showed a similar scavenging activity to ascorbic acid and higher than BHT. DPPH assay evaluates the ability of antioxidants to scavenge free radicals. Hydrogen-donating ability is an index of the primary antioxidant activity. In our study WFB, that had the highest content of proanthocyanidins, showed a similar radical scavenging activity to the extracts (AEB and EEB) with higher phenols and flavonoids content than WFB. Proanthocyanidins certainly contributed to the free radical scavenging activity of the extracts, as demonstrated by others (Kimura et al., 2008; Spranger et al., 2008). The extracts presented $\mathrm{Fe}^{3+}$ reducing capacity similar to ascorbic acid and higher than BHT and it was also concentrationdependent. The maximum reducing power was achieved with extracts at $250 \mu \mathrm{g} / \mathrm{mL}$ (Figure $2 \mathrm{~B}$ ).
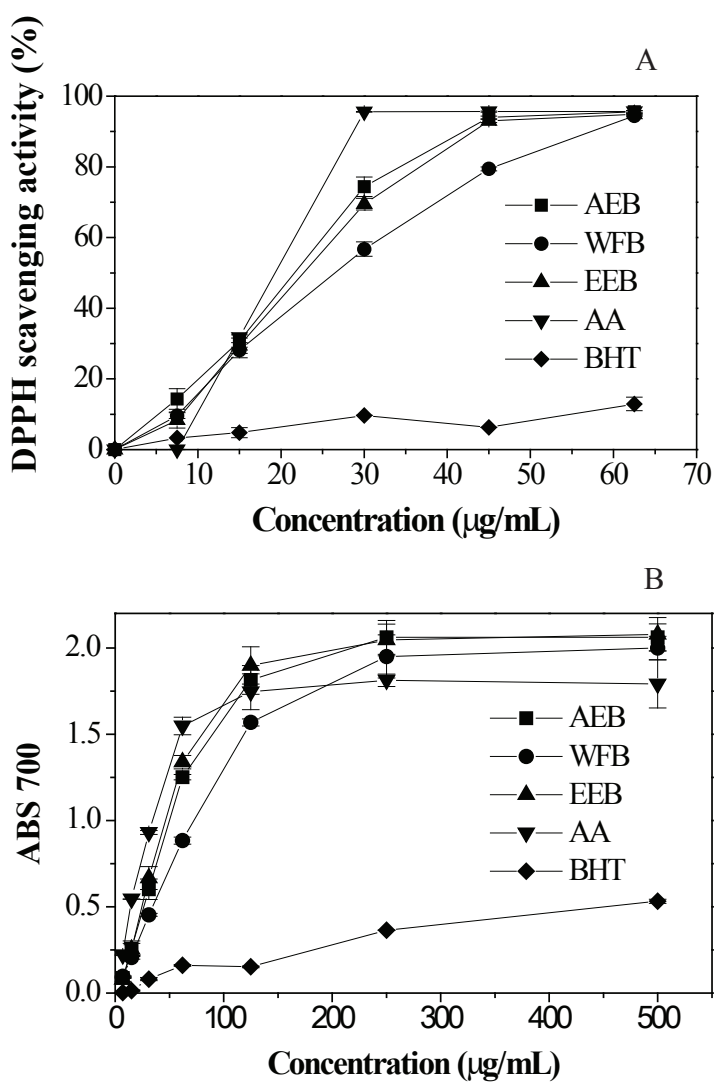

Figure 2. Antioxidant activity of barbatimão leaf extracts. A, DPPH scavenging activity; $B$, reducing power. AEB, aqueous extract; WFB, water fraction; EEB, ethanolic extract; AA, acid ascorbic (standard); BHT, butylated hydroxytoluene (standard). The results are mean $\pm \mathrm{SE}$ of five independent experiments performed in triplicate.

The interplay between free radicals and antioxidants is important in maintaining health and preventing the onset and progression of several pathologies (Halliwell, 2007a; Halliwell, 2007b).

The antioxidant activity of plant compounds has been attributed to various mechanisms, including prevention of chain initiation, binding of transition metal ion catalysts, decomposition of peroxides, prevention of continued hydrogen abstraction, reductive capacity and radical scavenging (Cos et al., 2003). The results of the present work indicate that the extracts act as antioxidants. The most important target for ROS in the carcinogenesis process is probably DNA. It is believed that antioxidant 
properties of these phytochemical materials protect cells from ROS-mediated DNA damage that can result in mutation and subsequent carcinogenesis and they may donate hydrogen to free radicals, leading to non-toxic species and therefore to inhibition of the propagation phase of lipid oxidation (Hosseinimehr et al., 2008).

The barbatimão leaf extracts might be reducing the micronuclei formation by scavenging the DNA damaging free radicals generated following $\mathrm{CP}$ exposure. Another possible extracts mechanism of action might involve selective removal of cells with DNA damage by apoptosis, which seems to be case of EEB. Proanthocyanidins and flavonoids are known to form a complex with proteins and monooxygenases metabolizing xenobiotics, due to the fact that the formers can act as multidentate ligands and thus are able to bind simultaneously to more than one point of the protein surface. The more the oligomeric nature, the more its association produces an increased antimutagenic activity towards the inhibition of the enzyme mediated genotoxicity of indirect acting mutagens (Bruni et al., 2006).

In conclusion, the present study demonstrates that WFB and EEB protected cells from the CP chemicalinduced genotoxicity and all extracts presented powerful antioxidant activity. Thus, our results support the beneficial effects of the barbatimão extracts as anticarcinogenic agent.

\section{Acknowledgments}

We gratefully acknowledge financial support (Process 1305-06) and fellowship (PRSF and LAF) received from FAPEMIG.

\section{References}

Almeida AC, Sobrinho EM, de Pinho L, Souza PNS, Martins ER, Duarte ER, Santos HO, Brandi IV, Cangussu AS, Costa JPR 2010. Toxicidade aguda dos extratos hidroalcoólicos das folhas de alecrim-pimenta, aroeira e barbatimão e do farelo da casca de pequi administrados por via intraperitoneal. Cienc Rural 40: 200-203.

Anvisa 2004. Resolução-RE No. 90 da Agência Nacional de Vigilância Sanitária. Guia para a realização de estudos de toxicidade pré-clínica de fitoterápicos.

Audi EA, Toledo DP, Peres PG, Kimura E, Pereira WK, Melo JC, Nakamura C, Alves-do-Prado W, Cumam RK, BersaniAmado CA 1999. Gastric antiulcerogenic effects of Stryphnodendron adstringens in rats. Phytother Res 13: 264-266.

Basile A, Ferrara L, Del Pezzo M, Meled G, Sorbo S, Bassi P, Montesano D 2005. Antibacterial and antioxidant activities of ethanol extract from Paullinia cupana Mart. J Ethnopharmacol 102: 32-36.
Belitsky GA, Yakubovskaya MG 2008. Genetic polymorphism and variability of chemical carcinogenesis. BiochemistryMoscow 73: 543-554.

Boudet AM 2007. Evolution and current status of research in phenolic compounds. Phytochemistry 68: 2722-2735.

Bruni R, Rossi D, Muzzoli M, Romagnoli C, Paganetto G, Besco E, Choquecillo F, Peralta K, Lora WS, Sacchetti G 2006. Antimutagenic, antioxidant and antimicrobial properties of Maytenus krukovii bark. Fitoterapia 77: 538-545.

Cos P, De Bruyne T, Hermans N, Apers S, Berghe DV, Vlietinck AJ 2003. Proanthocyanidins in health care: current and new trends. Curr Med Chem 11: 1345-1359.

Costa MA, Ishida K, Kaplum V, Koslyk EDA, Mello JCP, Ueda-Nakamura T, Dias Filho BP, Nakamura CV 2010. Safety evaluation of proanthocyanidin polymer-rich fraction obtained from stem bark of Stryphnodendron adstringens (Barbatimao) for use as a pharmacological agent. Regul Toxicol Pharmacol 58: 330-335.

DeSiervi A, Vazquez ES, Rezaval C, Rossetti MV, Del Batlle AM 2002. Delta-aminolevulinic acid cytotoxic effects on human hepatocarcinoma cell lines. BMC Cancer 2: 6 .

Diwanay S, Chitre D, Patwardhan B 2004. Immunoprotection by botanical drugs in chemotherapy. J Ethnopharmacol 90: 49-55.

Ebrahimzadeh MA, Pourmorad F, Bekhradnia AR 2008. Iron chelating activity, phenol and flavonoid content of some medicinal plants from Iran. African J Biotech 7: 31883192.

Edenharder R, Frangart J, Hager M 1998. Protective effects of fruits and vegetables against in vivo clastogenicity of cyclophosphamide or Benzo[ $\alpha]$ pyrene in mice. Food Chem Toxicol 36: 637-645.

Foo LY, Porter LJ 1980. The phytochemistry of proanthocyanidin polymers. Phytochemistry 19: 1747-1754.

Gulcin I, Oktay M, Kufrevioglu OI, Aslan A 2002. Determination of antioxidant activity of lichen Cetraria islandica (L.) Ach. J Ethnopharmacol 79: 325-329.

Halliwell B 2007a. Oxidative stress and cancer: have we moved forward? Biochem J 401: 1-11.

Halliwell B 2007b. Biochemistry of oxidative stress. Biochem Soc Trans 35: 1147-1150.

Hosseinimehr SJ, Azadbakht M, Abadi AJ 2008. Protective effect of hawthorn extract against genotoxicity induced by cyclophosphamide in mouse bone marrow cells. Environ Toxicol Pharmacol 25: 51-56.

Hu C, Zhang Y, Kitts DD 2000. Evaluation of antioxidant and prooxidant activity of bamboo Phyllostachys nigra var. henonis leaf extract in vitro. J Agr Food Chem 48: 31703176.

Ishida K, Mello JC, Cortez DA, Filho BP, Ueda-Nakamura $\mathrm{T}$, Nakamura CV 2006. Influence of tannins from Stryphnodendron adstringens on growth and virulence factors of Candida albicans. J Antimicrob Chemother 58: 942-949.

Ishida K, Rozental S, de Mello JC, Nakamura CV 2009. Activity 
Protective action against chemical-induced genotoxicity and free radical

of tannins from Stryphnodendron adstringens on Cryptococcus neoformans: effects on growth, capsule size and pigmentation. Ann Clin Microbiol Antimicrob 8: 29.

KimuraY, Ito H, Kawaji YM, Ikami T, Hatano T 2008. Characterization and antioxidative properties of oligomeric proanthocyanidin from prunes, dried fruit of Prunus domestica L. Biosci Biotechnol Biochem 72: 1615-1618.

Lima JCS, Martins DTO, De Souza PT, 1998. Experimental evaluation of stem bark of Stryphnodendron adstringens (Mart.) Coville for anti-inflammatory activity. Phytother Res 12: 218-220.

Lopes GC, Sanches ACC, Nakamura CV, Dias Filho BP, Hernandes L, de Mello JCP 2005. Influence of extracts of Stryphnodendron polyphyllum Mart. and Stryphnodendron obovatum Benth. on the cicatrisation of cutaneous wounds in rats. J Ethnopharmacol 99: 265-272.

Lopes GC, Machado FAV, Toledo CEM, CM, Mello JCP 2008. Chemotaxonomic significance of 5-deoxyproanthocyanidins in Stryphnodendron species. Bioch Syst Ecol 36: 925-931.

Mathew S, Abraham ET 2004. In vitro antioxidant activity and scavenging effects of Cinnamomum verum leaf extract assayed by different methodologies. Food Chem Toxicol 44: 198-206.

Melo JO, Endo TH, Bersani-Amado LE, Svidzinski AE, Baroni S, Mello JCP, Bersani-Amado CA 2007. Effect of Stryphnodendron adstringens (barbatimão) bark on animal models of nociception. Rev Bras Ciênc Farm 43: 465-469.

Mello JCP, Petereit F, Nahrstedt A 1996a. Flavan-3-ols and prodelphinidins from Stryphnodendron adstringens. Phytochemistry 41: 807-813.

Mello JCP, Petereit F, Nahrstedt A 1996b. Prorobinetinidins from Stryphnodendron adstringens. Phytochemistry 42: 857-862.

Mello JCP, Petereit F, Nahrstedt A 1999. A dimeric proanthocyanidin from Stryphnodendron adstringens. Phytochemistry 51: 1105-1107.

Murata M, Suzuki T, Midorikawa K, Oikawa S, Kawanishi S 2004. Oxidative DNA damage induced by a hydroperoxide derivative of cyclophosphamide. Free Radic Biol Med 37: 793-802.

Nagar S 2010. Pharmacokinetics of anti-cancer drugs used in breast cancer chemotherapy. Adv Exp Med Biol 678:124-132.

Nakagawa K, Hidaka T, Kitano M, Asakura M, Kamigaito T, Noguchi T, Hosoe K 2008. Genotoxicity studies on licorice flavonoid oil (LFO). Food Chem Toxicol 46: 2525-2532.

Natarajan AT 2002. Chromosome aberrations: past, present and future. Mut Res 504: 3-16.

Oktay M, Gulçin I, Kufrevioglu OI 2003. Determination of in vitro antioxidant activity of fennel (Foeniculum vulgare) seed extracts. Lebenson Wiss Technol 36: 263-271.

Okuda T 2005. Systematics and health effects of chemically distinct tannins in medicinal plants. Phytochemistry 66: 2012-2031.

Oyaizu M 1986. Studies on product of browning reaction prepared from glucose amine. Jpn J Nutr 44: 307-315.

Panizza S, Rocha AB, Gecchi, R, Silva RAPS 1988. Stryphnodendron barbadetiman (Vellozo) Martius: teor em tanino na casca e sua propriedade cicatrizante. Rev Ciênc Farmac 10: 101-106.

Paolini M, Nestle M 2003. Pitfalls of enzymes-based molecular anticancer dietary manipulations: food for thought. Mut Res 543: 181-189.

Prieto P, Pineda M, Aguilar M 1999. Spectrophotometric quantitation of antioxidant capacity through the formation of a phosphomolybdenum complex: specific application to the determination of vitamin E. Anal Biochem 269: 337-341.

Rai S, Wahile A, Mukherjee K, Saha B P, Mukherjee PK 2006. Antioxidant activity of Nelumbo nucifera (sacred lotus) seeds. J Ethnopharmacol 104: 322-327.

Romero-Jiménez M, Campos-Sánchez J, Analla M, MuñozSerrano A, Alonso-Moraga Á 2005. Genotoxicity and anti-genotoxicity of some traditional medicinal herbs. Mut Res 585: 147-155.

Rosch D, Bergmann M, Knorr D, Kroh LW 2003. Structureantioxidant efficiency relationships of phenolic compounds and their contribution to the antioxidant activity of sea buckthorn juice. J Agric Food Chem 51: 4233-4239.

Santos SC, Costa WF, Ribeiro JP, Guimarães DO, Ferri PH, Ferreira HD, Seraphin JC 2002. Tannin composition of barbatimão species. Fitoterapia 73: 292-299.

Spranger I, Sun B, Mateus AM, Freitas V, Ricardo-da-Silva JM 2008. Chemical characterization and antioxidant activities of oligomeric and polymeric procyanidin fractions from grape seeds. Food Chem 108: 519-532.

Sugumar E; Abraham P, Kanakasabapathy I 2007. Normal plasma creatinine level despite histological evidence of damage and increased oxidative stress in the kidneys of cyclophosphamide treated rats. Clin Chim Acta 376: 244-245.

Yen G, Wu J 1999. Antioxidant and radical scavenging properties of extracts from Ganoderma tsugae. Food Chem 65: 375-379.

\section{*Correspondence}

Cibele M. C. Paiva Gouvêa

Instituto de Ciências da Natureza, Universidade Federal de Alfenas

Rua Gabriel Monteiro da Silva, 700, 37130-000 Alfenas-MG, Brazil

cibele.gouvea@unifal-mg.edu.br

Tel.: +55353299 1419/ Fax: + 553532991067 